\title{
ASSESSMENT OF THE NEUTRALIZING POTENCY OF OVINE ANTIVENOM IN A SWISS MICE MODEL OF Bothrops jararaca ENVENOMING
}

\author{
FERREIRA J. (2), BASTOS M. F. (1), PELIZON A. C. (1), PERES C. M. (1), \\ CAVALCANTE D. P. (1), SARTORI A. (1)
}

(1) Department of Microbiology and Immunology, Institute of Biosciences, UNESP São Paulo State University, Botucatu, São Paulo, Brazil; (2) Institute of Physics, University of São Paulo (USP), São Carlos, São Paulo, Brazil.

\begin{abstract}
Alternative sources of anti-ophidic serum are being investigated due to the secondary effects associated with types I and II hypersensitivity reactions. In the present study we raised and evaluated the protective effect of an ovine antibothropic serum in a Swiss mice envenoming model. Ovine antiserum was obtained by immunization with seven increasing doses of bothropic venom associated with adjuvants. The neutralizing ability was tested by the lethal activity $\left(2 L_{50}\right)$ neutralization and serum and splenic venom levels after antivenom administration to experimentally envenomed mice. The antiserum effect on local edema was also tested by injection of venom/antivenom mixtures into the mice footpads. Ovine antiserum neutralized lethal activity and also significantly decreased serum and splenic venom levels. However, this antiserum was not able to mediate any protective effect on edema triggered by bothropic venom.
\end{abstract}

KEY WORDS: Bothrops jararaca venom, ovine antiserum, venom levels, edema, ELISA.

\section{CORRESPONDENCE TO:}

A. SARTORI, Departamento de Microbiologia e Imunologia - Instituto de Biociências, Universidade Estadual Paulista (UNESP), Botucatu, São Paulo, Brasil, 18618-000. Phone: +55 143811 6058. Fax: +55 143815 3744. Email: sartori@ibb.unesp.br. 


\section{INTRODUCTION}

Ophidic accident is a serious health problem for tropical countries (6). In Brazil, the majority of snakebites are caused by species classified into the genus Bothrops (8). Envenomations by different Bothrops species present a similar pathophysiological condition characterized by systemic disturbances such as hemorrhage, coagulopathies, cardiovascular shock and renal alterations $(10,17)$. Venoms from these snakes also induce, both in humans and experimental animals, a prominent local edema, which, besides being responsible for significant fluid loss, can contribute to other detrimental effects of the venom by causing tissue compression and ischemia (19).

The most effective therapy to counteract toxic effects of ophidic venoms is treatment with specific antiserum produced in horses. However, this kind of therapy can be associated with side effects as types I and III hypersensitivities (13). Alternative antibody sources, devoid of deleterious effects, are highly desirable. Sjostrom et al. (31) compared monospecific antivenoms raised in sheep against a variety of snake venoms, with commercially available antisera. They observed that ovine antivenoms generally contained higher concentration of specific antibodies in comparison with equine derived material. In addition, the ovine product usually provided better in vivo protection to mice than the equine counterpart (31). Easier ovine management, comparing to equines, has also stimulated sheep usage to generate antivenoms. Antisera to different snake venoms have been raised in sheep by Instituto Clodomiro Picado, including antiserum against Bothrops asper (11, 12, 22, 34).

Bothropic venom has a multiplicity of biological effects due to a complex venom mixture. Even though many components are already purified and characterized, the antivenom is usually raised against the whole mixture. A very well accepted methodology to evaluate the efficacy of these antivenoms is serum neutralization that consists in the in vitro incubation of venom with different antiserum concentrations. These mixtures are then injected into mice by the intraperitoneal (IP) route followed by determination of the dose that protects $50 \%$ of the animals from the ophidic venom lethal activity. Due to the severity of the edema and hemorrhage associated with this venom in particular, techniques were also developed to evaluate the neutralizing ability of the antiserum towards these effects (14). Another useful parameter to ascertain the neutralizing ability of an antiserum is the determination of serum venom concentration after antiserum administration. A variety of enzyme- 
linked immunosorbent assays (ELISA) were optimized to determine the serum venom levels in humans and experimental models $(2,33)$.

In the present study we raised an ovine antibothropic serum and investigated its protective effect in a model of murine envenoming.

\section{MATERIALS AND METHODS}

\section{Animals}

Male Swiss mice, aged 4-6 weeks, and two female Norfolk rabbits (Botucatu Strain, 2-3 kg) were supplied by the Central Animal Facility of São Paulo State University (UNESP), Botucatu, São Paulo. The animals were kept at the Animal Facility of the Department of Microbiology and Immunology throughout the experiments with free access to food and water. Four ovines of Ideal breed (65-70 Kg), aged 3-11 years old, were kept at the Veterinarian Hospital at UNESP, Botucatu.

\section{Venom}

A pool of lyophilized venoms was obtained from various adult specimens of Bothrops jararaca snakes kept at the Center for the Study of Venoms and Venomous Animals (CEVAP - UNESP, Botucatu, São Paulo). After lyophilization, the material was stocked a $-40^{\circ} \mathrm{C}$. For usage, the venom was diluted in endotoxin free salt solution.

\section{Ovine antibothropic serum}

The general vaccination protocol was based on the procedure developed at Institute Clodomiro Picado, Costa Rica (9). Briefly, the animals were immunized with seven doses of bothropic venom. The following doses: $0.5 ; 1 ; 3 ; 9 ; 18 ; 30$; and $45 \mathrm{mg}$ were injected by subcutaneous (SQ) route at days $0 ; 15 ; 30 ; 40 ; 50 ; 60$; and 70 , respectively. The first dose was associated with complete Freund's adjuvant (CFA), the second one with incomplete Freund's adjuvant (IFA) and the remaining doses with $\mathrm{Al}(\mathrm{OH})_{3}$. Booster effect on antiserum levels was measured by an indirect ELISA. The antiserum used in this investigation was obtained from one animal (N.1572), whose maximum title was observed 30-40 days after the first immunization. Further boosters did not significantly affect the specific antibody level. The last antibody sample, obtained 10 days after the last venom dose, was used due to its expected higher affinity. 


\section{Rabbit antibothropic serum}

Two rabbits were immunized by SQ route with $250 \mathrm{ng}$ of $B$. jararaca venom emulsified with $0.5 \mathrm{ml}$ of CFA, followed by three other SQ inoculations of $100 \mathrm{ng}$ venom emulsified with $0.5 \mathrm{ml}$ of IFA. Time interval among inoculations was 10 days. Two weeks after the last dose, animals were bled and serum kept at $-20^{\circ} \mathrm{C}$ until use.

\section{$L D_{50}$ and lethal activity neutralization}

Lethal toxicity of $B$. jararaca venom was assessed in Swiss male mice by IP injection of various venom concentrations. The $\mathrm{LD}_{50}$ was established according to Rolin Rosa et al. (27). To evaluate the ability of the non-fractionated ovine antivenom to neutralize the venom lethal activity, two animal groups were compared: one that received $2 L D_{50}$, and another that received a mixture containing $2 L_{50}$ of venom plus the antibothropic serum obtained in sheep. Both groups were injected by IP route (200 $\mu \mathrm{l}$ final volume) and the animals were inspected during 96 hours for survival percentage.

\section{ELISA for venom quantification}

This assay was standardized according to Barral-Netto et al. (5) and also to our previous experience in this field (7). Polypropylene microtiter plates (Nunc) were coated with $100 \mu$ l dilution of $F\left(a b^{\prime}\right)_{2}$ fraction from horse anti-B. jararaca venom diluted 1:200 in carbonate-bicarbonate buffer $\left(\mathrm{pH} \mathrm{9.6)}\right.$ for $1 \mathrm{~h}$ at $37^{\circ} \mathrm{C}$. The wells were then washed five times with $200 \mu \mathrm{l}$ phosphate buffered saline (PBS) containing $0.05 \%$ Tween 20 (PBS-T) and incubated overnight at $4{ }^{\circ} \mathrm{C}$ with $3 \%$ low-fat milk in carbonate-bicarbonate buffer as a blocking step. After another washing cycle, a $2 \mathrm{~h}$ incubation was performed with either various concentrations of $B$. jararaca venom (ranging from $65 \mathrm{ng} / \mathrm{ml}$ to $500 \mathrm{pg} / \mathrm{ml}$ ) or samples from serum or splenic homogenates. After another washing step, $100 \mu \mathrm{l}$ of rabbit antibothropic serum (1:200) was added to the plate and incubated $1 \mathrm{~h}$ at $37^{\circ} \mathrm{C}$. The wells were subsequently washed and $100 \mu \mathrm{l}$ of goat anti-rabbit IgG conjugated to peroxidase (1:8000) were added. The plates were incubated for $1 \mathrm{~h}$ at $37^{\circ} \mathrm{C}$. The wells were then washed and incubated with $100 \mu \mathrm{l}$ of an enzimatic substrate containing $0.04 \%$ orthophenylenediamine plus $0.012 \%$ hydrogen peroxide in citrate-phosphate buffer $(\mathrm{pH}$ 5.0) for about 15 min at room temperature in the dark. The reaction was stopped by 
addition of $50 \mu \mathrm{l}$ of $2 \mathrm{M}$ sulfuric acid and the absorbance values were measured at $492 \mathrm{~nm}$ using an ELISA reader (Multiskan Spectrophotometer, manufactured in Finland by Labsystems).

\section{Serum and splenic venom levels}

The ability of the antiserum to neutralize venom levels was assayed by quantification of venom in serum and spleen as has been described $(4,30)$. The following experimental procedure was used: animals were allocated in 5 groups (5 animals each). Each group received $2.5 \mu \mathrm{g} / \mathrm{g}$ of bothropic venom by IP route. Treatment with antivenom was done concomitantly or after venom inoculation (15 minutes, 1 hour, or 2 hours). The ovine antibothropic serum was diluted 1:10 and delivered in a final 200 $\mu$ volume, being also administered by IP route. The fifth group was left untreated and used as control. Six hours after envenoming, animals were sacrificed and blood and spleen samples were collected. Blood samples were obtained by cardiac puncture and spleen homogenates were prepared by disrupting the splenic tissue on a sterile fine nylon screen with $500 \mu$ of RPMI 1640 medium. Blood samples and splenic homogenates were centrifuged and supernatants were stocked at $-20^{\circ} \mathrm{C}$ for further venom quantification by ELISA.

\section{Effect of ovine antibothropic serum on local edema}

The methodology used to test the ability of the sheep antivenom to neutralize edema induced by bothropic venom was similar to the one described by Leon et al. (22) Initially, the edema was quantified in mice footpad injected with venom by measuring its increase in thickness with a low-pressure caliper. B. jararaca venom was then diluted in a saline solution ( $\mathrm{NaCl} 0.85 \%)$ and $50 \mu$ of various venom concentrations were injected into one footpad. Saline solution $(50 \mu \mathrm{l})$ was injected into the other footpad as a control. The dose of $1.6 \mu \mathrm{g} / \mathrm{g}$ animal was chosen to test the antiserum neutralizing ability because it determined an edema without hemorrhage and necrosis (not shown). Edema neutralizing activity was determined by inoculation of a 50 ul mixture of venom and antivenom (1:20 final dilution), previously incubated during 30 minutes at room temperature. Mice footpads injected with saline solution, venom or antivenom were also measured and used as controls. Footpads thickness 
was evaluated before and after (20 $\mathrm{min}, 1,2,3,4,5,6$, and 24h) venom, antivenom or venom-antivenom mixture inoculation.

\section{RESULTS}

\section{Lethal activity neutralization}

The $L_{50}$ for the bothropic venom batch used in this study was $2.5 \mu \mathrm{g} / \mathrm{g}$ mouse. Animals injected with $2 L_{50}$ survived only 3 hours and presented a severe hemorrhage in the peritoneal cavity. Animals that received the same venom dose previously associated with the whole antivenom (final dilution 1:10) presented 100\% survival in a 96 hours follow-up. A very discrete hemorrhage was observed in the peritoneal cavity at this period (result not shown).

\section{Neutralization of venom in serum and spleen}

Antiserum administration by the IP route efficiently neutralized serum venom levels. As we can observe in Figure 1 , the venom neutralization ability was clearly associated with the time elapsed between the venom inoculation and the antiserum therapy. Simultaneous administration of venom and antivenom or a 15 minutes delay in the antiserum inoculation completely neutralized serum venom levels (Figure 1a). One or two hours delay in the antivenom administration was still associated with significant venom neutralization. Neutralization of splenic venom levels was also very effective. As shown in Figure 1b, antivenom administration, independently of the time that this procedure was performed, was always able to significantly decrease venom levels in the spleen.

\section{Ovine antiserum effect on edema}

As shown in Figure 2, antivenom raised in sheep was not able to decrease edema induced by bothropic venom. Even though this effect was investigated during various lengths of time after venom-antivenom inoculation, only the results observed at 20 minutes and 2 hours were showed. 


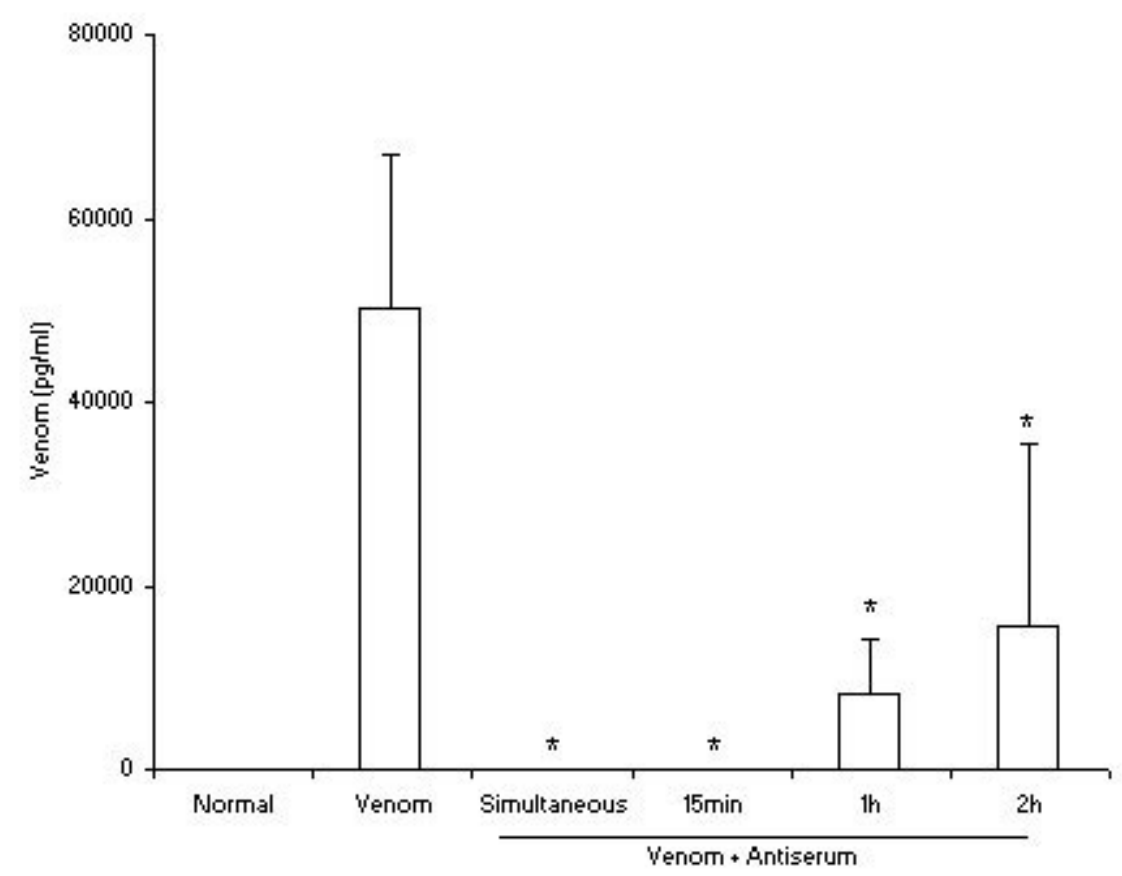

Figure 1a - Seric venom levels

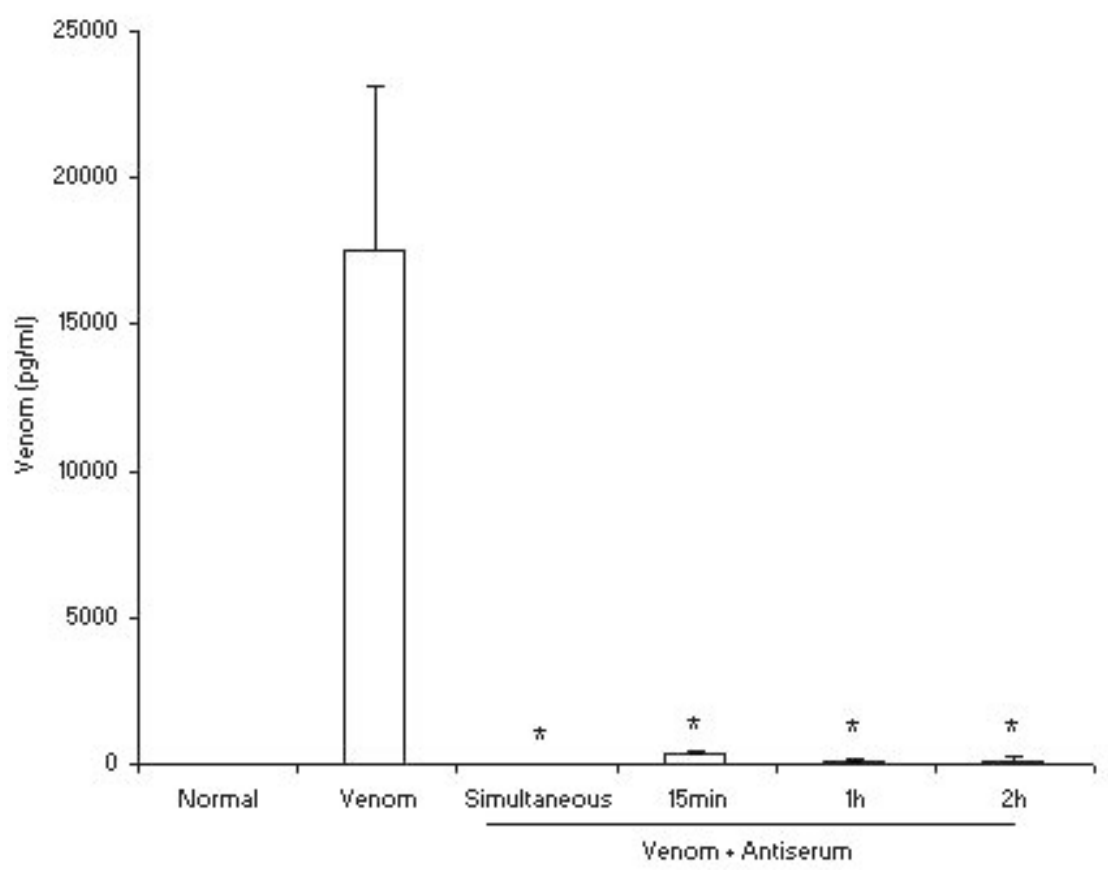

Figure $1 b$ - Splenic venom levels

Figures $1 \mathrm{a}$ and $1 \mathrm{~b}$. Neutralizing effect of ovine antibothropic venom on venom levels. Swiss male mice were injected with bothropic venom and treated with ovine antiserum. Blood samples and spleen homogenates were obtained 6 hours after envenomation. Venom levels were determined by ELISA and results represent the mean of 5 animals +/- SD. (1a) seric levels; (1b) splenic levels. Experiment was repeated twice with similar results. ${ }^{*} p<0.05$ in comparison with the venom group (not treated with antiserum). 


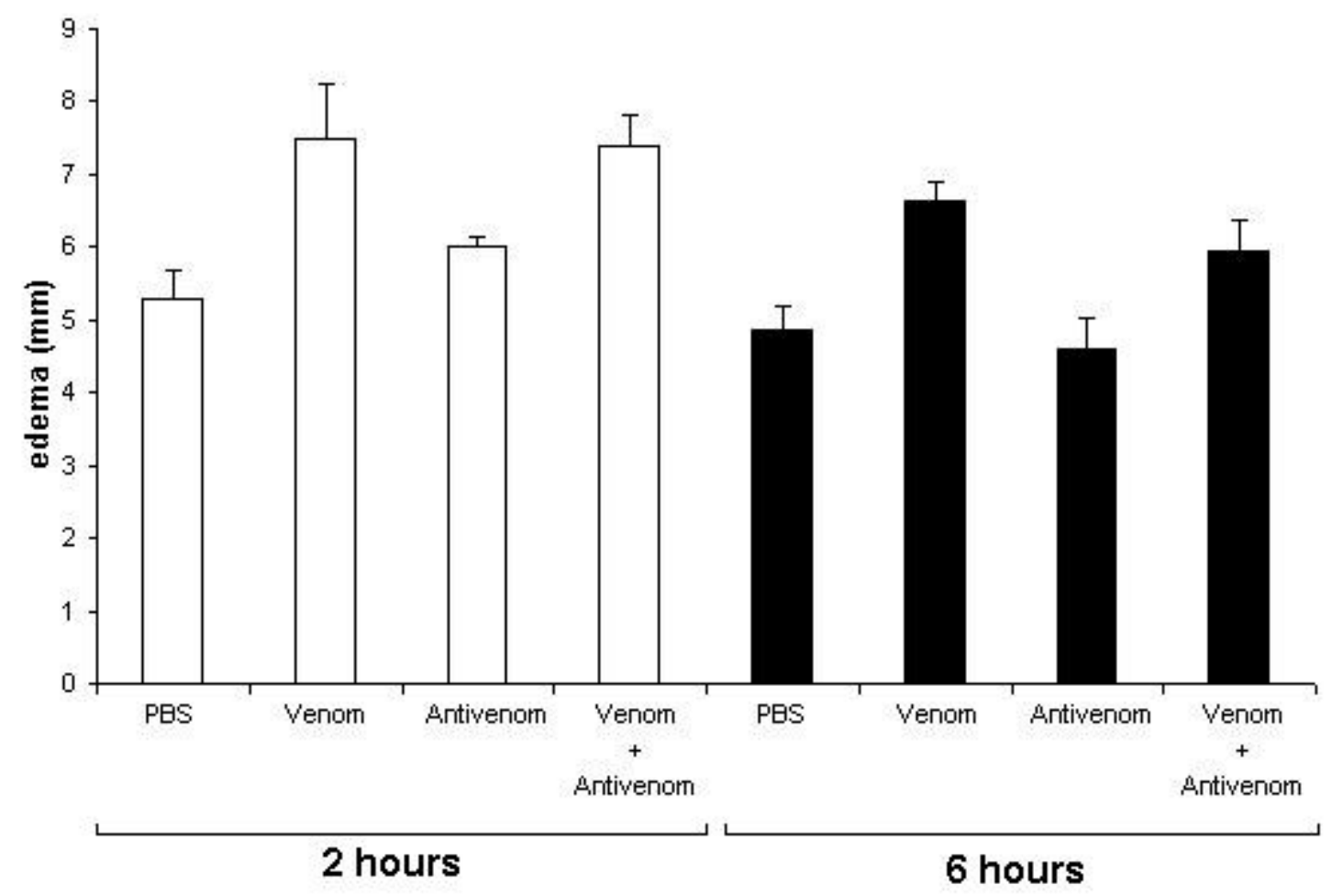

Figure 2. Effect of ovine antibothropic serum on edema induced by Bothrops jararaca venom. Venom or a mixture of venom-antivenom was injected in the right footpad. Left footpads were injected with salt solution, venom or antivenom. Increases in thickness were measured with a caliper after 2 and $6 \mathrm{~h}$. Results represent the mean of 5 animals \pm SD. No statistical differences were observed between Venom and Venom + Antivenom groups.

\section{DISCUSSION}

Estimates of global mortality from snakebites have been reported to range from 50.000 to 100.000 per year $(32,13)$. Bothropic and polyvalent antivenoms constitute the major therapeutic resource to treat snakebite envenomations in Brazil and Central America $(10,8)$. Equine-derived antivenoms are the most common source for these immunobiologicals $(1,16)$. However, adverse reactions mainly associated with the Fc activating complement ability of horse IgG have been described (21). For cases of hypersensitivity to horse serum, other animals have been tested as source of antivenoms; good results have been observed with goats, rabbits, and sheep (23, 24, 29).

The present study was undertaken to investigate, by using an experimental model, whether a monospecific serum raised in ovine would be effective to neutralize bothropic venom. To approach this question, different parameters were investigated: neutralization of venom lethal activity, serum and splenic venom levels, and the 
antiserum ability to neutralize the edematogenic venom effect. Samples obtained from Swiss mice experimentally injected with $1 L_{50}$ by IP route were used to evaluate the serum and splenic venom levels. Animals injected in the footpad with a minimal edematogenic venom dose, previously determined, were used to investigate the anti-edematogenic serum ability.

Initially, we observed that non-diluted sheep antivenom was able to neutralize venom lethal activity associated with $2 \mathrm{LD}_{50}$. In addition to this protection, this product was also able to clearly diminish the extension of peritoneal hemorrhage observed by visual inspection (not shown). This neutralizing ability was then checked by determination of the serum venom levels. At first, this was evaluated by the previous incubation of a venom-antivenom mixture followed by its inoculation into mice. By this procedure it was observed that antiserum diluted 1:10 was able to decrease the serum venom to undetectable levels. To better mimic the heterologous serum therapy used to treat envenomed patients, the efficacy of antivenom doses, administered at distinct periods after venom inoculation, was compared. As expected, neutralization decreased as the time lapse between envenomation and treatment increased. Even thought treatment administered at 1 or 2 hours after the beginning of envenomation did not completely neutralize the venom, this procedure significantly decreased the serum venom levels. Similar results, emphasizing the neutralizing ability of antisera raised in sheep, have been demonstrated by other authors. Sjostrom et al. (31) observed that antibodies obtained by immunizing sheep with crotalic venom were more effective than their equine counterparts in preventing lethal toxicity in mice, in inhibiting the venom pharmacological effects, and in neutralizing phospholipase A2 activity. Netto et al. (23) also evaluated the capacity of sheep as serum producers against crotalic venom. They observed that sheep immunized with Cobalt 60 gamma-irradiated venom presented a powerful and lasting humoral immune response. Interestingly, treatment with gamma radiation decreased the venom toxicity but improved the potency of the corresponding antiserum.

The potency of the sheep antiserum used in our study was not compared with commercially available antiophidian sera of equine origin. In addition to this comparison, it is specially important to further investigate the neutralizing properties by using separate IgG from whole serum and $F\left(a b^{\prime}\right)_{2}$ fragment purified by enzymatic treatment, as it has been adopted for horse antiserum $(20,35)$. In addition to the benefits described above, other general advantages reinforce the potential 
application of sheep in antivenom production: greater availability, easier handling, lower acquisition, and also lower maintenance costs. In addition, as reported by Sjostrom et al. (31), these animals presented greater tolerance to Freund's adjuvants and other adjuvants, showing no lesions at the immunization sites. These authors also demonstrated that high IgG levels were quickly induced with no detection of IgGT. This is very useful information because high levels of heavily glycosylated IgGT antibodies are present in equine serum. IgGT is powerfully immunogenic when injected into other species, including humans, and may contribute to antivenom reactions (31). It is important to stress, however, that some severe side effects were also reported after serum therapy with ovine Fab antiserum (20).

It has been described that venom distributes mainly in the tissue compartments ( 3 , $25)$. On the other hand, IgG and $F\left(a b^{\prime}\right)_{2}$ spread only feebly out of the plasma volume, and therefore are not very effective for venom neutralization within the tissues (13). In this context and also because spleen weight was clearly diminished in animals treated with $2 \mathrm{LD}_{50}$ (not shown), suggesting a possible higher concentration of venom in the spleen, venom amounts were also quantified in spleen homogenates. Antivenom was very efficient to neutralize venom levels in the spleen. Interestingly, even antivenom doses administered at later periods of time ( 1 or $2 \mathrm{~h}$ after envenomation) were still able to significantly decrease the venom levels in this organ. Certainly, evaluation of spleen homogenates from animals previously submitted to a perfusion procedure, as described by Domingos et al. (15), would be more adequate and give more valuable information.

The ovine antiserum was not able to neutralize the edematogenic effect. This is, at least in some aspects, in accordance with related literature. Venom-induced local tissue damage (hemorrhage, myonecrosis, and edema) is considered difficult to control during the treatment of envenomations, since these effects develop rapidly after venom inoculation (28). In experimental envenomation models even the incubation of antisera and venom, prior to injection into animals and similar to the procedure we adopted, was not able to neutralize the edematogenic effect (18). Other reports, however, show opposite findings. Rojas et al. (26) demonstrated that equine-derived antivenoms were able to neutralize lethal, hemorrhagic, edemaforming, myotoxic, coagulant, and defibrinating activities associated with Bothrops $\mathrm{sp}$ snake venoms. Also, whole IgG molecules and Fab fragments derived from sheep antivenoms were able to neutralize local hemorrhage, edema, and myonecrosis 
induced by Bothrops asper venom (22). One possibility to explain the inability of our antiserum preparation to block edema development is the low amount of antiserum used.

Our experimental observations show, therefore, that serum raised in ovines was able to neutralize bothropic venom lethal activity and also to significantly decrease the venom levels in serum and spleen. These results, together with other similar reports, suggest that sheep are potential animals to be used in antibothropic serum production.

\section{ACKNOWLEDGEMENTS}

The authors thank the Center for the Study of Venoms and Venomous Animals (CEVAP - UNESP, Botucatu) for their generous supply of lyophilized B. jararaca venom; Dr. Maria Terezinha Serrão Peraçoli for enzyme-labelled anti-rabbit globulin conjugate; the Department of Tropical Disease for horse $\mathrm{F}\left(\mathrm{ab}^{\prime}\right)_{2}$ anti-venom donation; and Dr. Ramon Kaneno (UNESP-Botucatu) for helpful discussion.

\section{REFERENCES}

1 ANGULO Y., ESTRADA R., GUTIERREZ JM. Clinical and laboratory alterations in horses during immunization with snake venoms for the production of polyvalent (Crotalinae) antivenom. Toxicon, 1997, 35, 81-90.

2 AUDEBERT F., SORKINE M., BON C. Envenoming by viper bites in France: clinical gradation and biological quantification by ELISA. Toxicon, 1992, 30, 599-609.

3 AUDEBERT F., URTIZBEREA M., SABOURAUD A., SCHERRMANN JM., BON C. Pharmacokinetics of Vipera aspis venom after experimental envenomation in rabbits. J. Pharmacol. Exp. Ther., 1994, 268, 1512-7.

4 BARBOSA CF., RODRIGUES RJ., OLORTEGUI CC., SANCHEZ EF., HENEINE LG. Determination of the neutralizing potency of horse antivenom against bothropic and crotalic venoms by indirect enzyme immunoassay. Braz. J. Med. Biol. Res., 1995, 28, 1077-80.

5 BARRAL-NETTO M., SCHRIEFER A., VINHAS V., ALMEIDA AR. Enzyme-linked immunosorbent assay for the detection of Bothrops jararaca venom. Toxicon, $1990,28,1053-61$. 
6 BARRAVIERA B., GARCIA FCM., FULINI DR., MARCONDES-MACHADO J., PEREIRA PCM., MENDES RP., SOUZA LR., ZORNOFF DCM., MEIRA DA. Estudo clínico e epidemiológico de doentes picados por serpentes venenosas na região de Botucatu (SP). J. Bras. Med., 1994, 67, 224-32.

7 BARRAVIERA B., SARTORI A., PEREIRA DA SILVA MF., KANENO R., PERAÇOLI MTS. Use of an ELISA assay to evaluate venom, antivenom, IgG and IgM human antibody levels in serum and cerebrospinal fluid from patients bitten by Crotalus durissus terrificus in Brazil. J. Venom. Anim. Toxins, 1996, 2, 14-27.

8 BOCHNER R., STRUCHNER CJ. Snake bite epidemiology in the last 100 years in Brazil: a review. Cad. Saúde Públ., 2003, 19, 7-16.

9 BOLANOS R., CERDAS L. Production and control of antivenin sera in Costa Rica. Bol. Oficina Sanit. Panam., 1980, 88, 189-96.

10 CARDOSO JL., FAN HW., FRANÇA FO., JORGE MT., LEITE RP., NISHIOKA SA., AVILA A., SANO-MARTINS IS., TOMY SC., SANTORO ML., CHUDZINSKI AM., CASTRO SCB., KAMIGUTI AS., KELEN EMA., HIRATA MH., MIRANDOLA RMS., THEAKSTON RDG., WARREL DA. Randomized comparative trial of three antivenoms in the treatment of envenoming by lanceheaded vipers (Bothrops jararaca) in São Paulo, Brazil. Q. J. Med., 1993, 86, 315-25.

11 CHAVES F., LORIA GD., SALAZAR A., GUTIERREZ JM. Intramuscular administration of antivenoms in experimental envenomation by Bothrops asper: comparison between Fab and IgG. Toxicon, 2003, 41, 237-44.

12 CHIPPAUX JP., GOYFFON M. Producers of antivenom sera. Toxicon, 1983, 21, 739-52.

13 CHIPPAUX JP., GOYFFON M. Venoms, antivenoms and immunotherapy. Toxicon, 1998, 36, 823-46.

14 CHRISTENSEN PA. Remarks on antivenin potency estimation. Toxicon, 1967, 5, 143-5.

15 DOMINGOS MO., TAKEHARA HA., LAING G., SNOWDEN KF., SELLS PG., MOTA I., THEAKSTON RDG. Detection and neutralization of $B$. jararaca venom in mice. Braz. J. Med. Biol. Res., 1994, 27, 2613-22. 
16 FERNANDES I., LIMA EX., TAKEHARA HA., MOURA-DA-SILVA AM., TANJONI I., GUTIERREZ JM. Horse IgG isotypes and cross-neutralization of two snake antivenoms produced in Brazil and Costa Rica. Toxicon, 2000, 38, 633-44.

17 GUTIERREZ JM. Clinical toxicology of snakebite in Central America. In: MEIER J., WHITE J. Eds. Handbook of clinical toxicology of animal venoms and poisons. Boca Raton: CRC Press, 1995: 645-65.

18 GUTIERREZ JM., LEON G., ROJAS G., LOMONTE B., RUCAVADO A., CHAVES F. Neutralization of local tissue damage induced by Bothrops asper (terciopelo) snake venom. Toxicon, 1998, 36, 1529-38.

19 GUTIERREZ JM., LOMONTE B. Local tissue damage induced by Bothrops snake venom. Mem. Inst. Butantan, 1978/1979, 42/43, 373-496.

20 KRIFI MN., EL AYEB M., DELLAGI K. The improvement and standardization of antivenom production in developing countries: comparing antivenom quality, therapeutical efficiency and cost. J. Venom. Anim. Toxins, 1999, 5, 128-41.

21 LEON G., MONGE M., ROJAS E., LOMONTE B., GUTIERREZ JM. Comparison between IgG and $F\left(a b^{\prime}\right)_{2}$ polyvalent antivenoms: neutralization of systemic effects induced by Bothrops asper venom in mice, extravasation to muscle tissue and potential for induction of adverse reactions. Toxicon, 2001, 39, 793801.

22 LEON G., VALVERDE JM., ROJAS G., LOMONTE B., GUTIERREZ JM. Comparative study on the ability of IgG and Fab sheep antivenoms to neutralize local hemorrhage, edema and myonecrosis induced by Bothrops asper (terciopelo) snake venom. Toxicon, 2000, 38, 233-44.

23 NETTO DP., CHIACCHIO SB., BICUDO PL., ALFIERI AA., NASCIMENTO N. Humoral response and neutralization capacity of sheep serum inoculated with natural and cobalt 60-irradiated Crotalus durissus terrificus venom (Laurenti, 1768). J. Venom. Anim. Toxins, 2002, 8, 297-314.

24 OSHIMA-FRANCO Y., HYSLOP S., PRADO-FRANCSECHI J., CRUZ-HOFLING MA., RODRIGUES-SIMIONI L. Neutralizing capacity of antisera raised in horses and rabbits against Crotalus durissus terrificus (South American rattlesnake) venom and its main toxin, crotoxin. Toxicon, 1999, 37, 1341-57. 
25 RIVIERE G., CHOUMET V., AUDEBERT F., SABOURAUD A., DEBRAY M., SCHERRMANN JM., BON C. Effect of antivenom on venom pharmacokinetics in experimentally envenomed rabbits: towards an optimization of antivenom therapy. J. Pharmacol. Exp. Ther., 1997, 281, 1-8.

26 ROJAS E., QUESADA L., ARCE V., LOMONTE B., ROJAS G., GUTIERREZ JM. Neutralization of four Peruvian Bothrops sp. snake venoms by polivalent antivenoms produced in Peru and Costa Rica: preclinical assessment. Acta Trop., 2005, 93, 85-95.

27 ROLIN ROSA R., FURLANETO SMP., VILARROEL MS. Contribuição ao estudo da determinação da DL50 do veneno de Crotalus durissus terrificus (LAURENTI, 1768) em Mus musculus. Mem. Inst. Butantan, 1973, 37, 131-3.

28 RUCAVADO A., LOMONTE B. Neutralization of myonecrosis, hemorrhage and edema induced by Bothrops asper snake venom by homologous and heterologous pre-existing antibodies in mice. Toxicon, 1996, 34, 567-77.

29 RUSSEL FE., TIMMERMAN WF., MEADOWS PE. Clinical use of antivenin prepared from goat serum. Toxicon, 1970, 8, 63-5.

30 SELVANAYAGAM ZE., GNANAVENDHAN SG., GANESH KA., RAJAGOPAL D., RAO PV. ELISA for detection of venoms from four medically important snakes of India. Toxicon, 1999, 37, 757-70.

31 SJOSTROM L., AL-ABDULLA IH., RAWAT S., SMITH DC., LANDON J. A comparison of ovine and equine antivenoms. Toxicon, 1994, 32, 427-33.

32 SWAROOP S., GRAB B. Snake bite mortality in the world. Bull. World Health Organ., 1954, 10, 35-76.

33 THEAKSTON RD., REID HA. Development of simple standard assay procedures for the characterization of snake venoms. Bull. World Health Organ., 1983, 61, 949-56.

34 THEAKSTON RD., WARRELL DA. Antivenoms: a list of hyperimmune sera currently available for the treatment of envenoming by bites and stings. Toxicon, 1991, 29, 1419-70.

35 THEAKSTON RDG., WARRELL DA., GRIFFITHS E. Report of a WHO workshop on the standardization and control of antivenoms. Toxicon, 2003, 41, 541-57. 